\title{
O Novo Design no Brasil: a construção de um conceito
}

The New Design in Brazil: the construction of a concept

\section{Adriana Dornas}

Universidade do Estado de Minas Gerais

adrianadornasmoura@gmail.com

Sebastiana Luiza Bragança Lana

Universidade do Estado de Minas Gerais

sebastiana.lana@gmail.com $\mathbf{x}$

Marcelina das Graças de Almeida

Universidade do Estado de Minas Gerais

marcelinaalmeida@yahoo.com.br

PROJËTICA

COMO CITAR ESTE ARTIGO:

DORNAS, Adriana; LANA, Sebastiana Luiza Bragança; ALMEIDA, Marcelina das Graças de. O Novo Design no Brasil: a construção de um conceito. Projética, Londrina, v. 11, n. 2, p. 179-205, 2020.

DOI: $10.5433 / 2236-2207.2020 v 11 \mathrm{n} 2 \mathrm{p} 179$

Submissão: 25-04-2019

Aceite: 25-07-2019

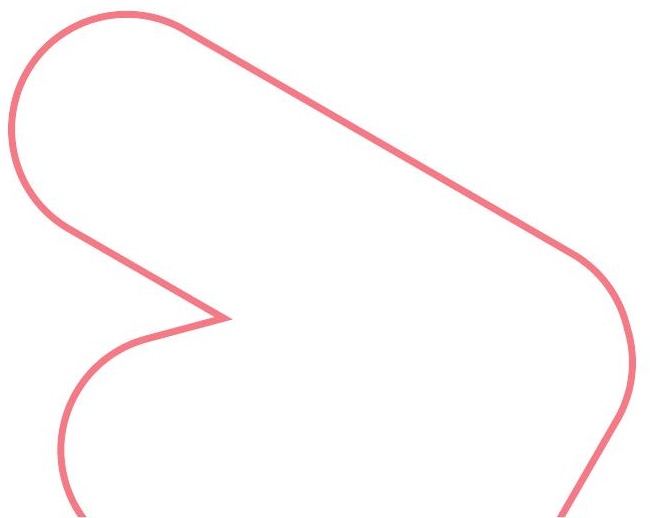


Projética, Londrina, v. 11, n. 2, p. 179-205, agosto 2020

RESUMO: O presente trabalho de revisão objetiva apresentar o conceito do Novo Design no Brasil. O aspecto fundamental dessa abordagem destaca o estado da arte de peças contemporâneas na sociedade pós-industrial, considerando os autores Beat Schneider, Andrea Branzi, Ezio Manzini \& Anna Meroni e outros. Além do mais, o desenvolvimento destas reflexões é mostrado focalizando as atividades de alguns designers na aplicação deste conceito.

Palavras-chave: Design brasileiro. Novo design. Pós-moderno. Design-arte.

ABSTRACT: This review aims to present the concept of New Design in Brazil. The fundamental aspect of this approach highlights the state-of-the-art of contemporary pieces in the post-industrial society, considering the authors Beat Schneider, Andrea Branzi, Ezio Manzini \& Anna Meroni, among others. Furthermore, in order to explain our thinking, we focus on activities of some Brazilian designers in the application of this concept.

Keywords: Brazilian design. New design. Postmodern. Art-design.

\section{INTRODUÇÃO}

A complexidade dos estudos que engloba o contexto da pós-modernidade dificulta a leitura de obras que se encontram na linha tênue entre arte e design. A década de 1980 foi um período de crescimento intenso para o design. E ficou conhecida como "a década do design" e que Schneider (2010) sintetiza com o conceito “Novo Design". 
Essa pós-modernidade presente na década de 1980, no cenário internacional, produziu, segundo Schneider (2010, p. 165), “um grande número de correntes do design, por vezes opostas". [...] e tornou-se uma "salada nada dogmática de abordagens e tendências, sem pretensões crítico-emancipatórias". O Novo Design se caracterizou por pensamentos independentes, ao separar indústria e funcionalismo, deslocando-o da produção em série.

A expressão Novo Design é utilizada como conceituação para compreensão do design contemporâneo, mas não se trata de uma visão dicotômica, pela qual se rejeita o passado em função do presente, mas de uma perspectiva de visualizar mudanças que estão sendo propostas por transformações sociais, culturais, econômicas e políticas sob as quais o design se constitui. Esse conceito foi elaborado pelos seguintes autores: Branzi (2006); Manzini e Meroni, (2009) e Schneider (2010). Desde então a intensificação da aproximação entre design e arte no Brasil e em outros lugares do mundo apresentaram um impulso vertiginoso, em que surgiram ações que estimularam a integração entre essas duas áreas.

\section{FUNDAMENTAÇÃO TEÓRICA}

\subsection{O CONCEITO DO NOVO DESIGN - APONTAMENTOS INICIAIS}

Percebe-se que o ambiente social é um espaço multicultural rico em simbolismos capazes de gerar linguagens próprias nas diversas criações, sejam nas artes ou no design. Esse último pode sofrer influências culturais, tanto no processo criativo quanto no uso dos materiais (BRANZI, 2006; DIAS, 2009; TAVARES, 2007). A teoria tem revelado que esse caminho leva o design a uma multiplicidade de possibilidades, suscitando um novo conceito que pode ser designado como Novo Design. 
Projética, Londrina, v. 11, n. 2, p. 179-205, agosto 2020

Foi na década de 1980 que o cenário mundial conheceu esse novo conceito registrado na linguagem das artes e do design mundial, o chamado Novo Design. Ressalta-se que o movimento Memphis, que surgiu na década de 1980, fundado pelo designer Ettore Sottsass (1917-2007), produziu correntes por vezes opostas "expressivas e puristas, ironizantes e historizantes, high-tech e artesanais", tratando esse Novo Design como "anti-design" (SCHNEIDER, 2010, p. 77). Nesse Novo Design, é perceptível a coexistência de várias configurações dos objetos, e as interseções entre arte e design gerou novas formas de linguagem, ou seja, formas híbridas.

O designer Dijon De Moraes (2006, p. 192) acredita que esse foi um período em que o design passou a ser entendido “[...] como metáfora de um conjunto de significados (conceitos) e de significância (valor)". Tais bases são fundamentais para o desenvolvimento dessa nova realidade de projetar.

Relembrando Manzini e Meroni (2009, p. 15), estes denominam como Novo Design essa realidade, que, para eles, trata-se da geração de modelos de produtos orientados por valores que vão além da própria funcionalidade. Schneider por sua vez, reforça o conceito de Novo Design pelas seguintes características:

[...] rejeição ao funcionalismo; influências de subculturas (punk, etc.) e do cotidiano; tratamento eclético de estilos históricos; ironia, humor e provocação; trabalho experimental; utilização de materiais não usuais; formação de grupos; desligamento da produção industrial em série; produção de peças únicas e pequenas séries; uso dos meios de comunicação como pódio; transposição dos limites entre o design e a arte (SCHNEIDER, 2010, p. 166).

Barroso Neto (1999) o denominou como "design autoral", mas Schneider (2010) considera que o trabalho imaginativo do designer sobressai de sua inspiração individual, denominando-o "designer-artista". Assim, pode-se perceber que as fronteiras tradicionais entre arte e design estão em constante convergência e num 
contexto de diluição de fronteiras. Para entender um pouco mais sobre essas convergências, as formulações propostas por Heinich (2014) com a transposição dos limites entre o design e a arte, traduzem e exemplificam os paradigmas da arte contemporânea que vão se reverberar e atingir o design contemporâneo.

Manzini e Meroni (2009) também conceituam o resultado dessa integração como Novo Design, ou seja, uma forma sistêmica de interação com iniciativas capazes de gerar outros modelos de objetos orientados por valores que vão além da funcionalidade. Os autores contextualizam essa questão ao afirmar que "[...] o designer é aquele que, mais do que outros profissionais, possui a capacidade e a possibilidade de criar novos modelos de referência, de imaginar novos estilos de vida com base nestas ordens diversas de valores e de qualidade" (MANZINI; MERONI, 2009, p. 14).

Bürdek (2006, p. 63) denomina esse momento do design como uma "[...] salada nada dogmática de abordagens e tendências", acreditando ser exatamente esse o conceito de Novo Design. Nesse Novo Design, se percebe a diluição das fronteiras entre arte e design e nesse design híbrido à arte, incorporam-se as relações entre os atores pertencentes ao mundo da arte. Assim pode-se perceber que várias são as denominações que os diversos autores apontam. E para elucidar melhor, o próximo tópico vai apontar os primeiros movimentos de construção do conceito do Novo Design no contexto mundial.

\subsection{O RECONHECIMENTO DOS PRIMEIROS MOVIMENTOS PARA A CONSTRUÇÃO DO CONCEITO DO NOVO DESIGN}

Em 1980 ocorreu em Linz, na Áustria, um evento onde se discutiu as questões fundamentais e foram apontados outros caminhos para a teoria do design, o evento ficou conhecido como "Forum Design" (SCHNEIDER, 2010). Neste 
Projética, Londrina, v. 11, n. 2, p. 179-205, agosto 2020

evento pioneiro do design pós-moderno, se discutiu toda história do design, assim como seu significado, o papel dos profissionais e a relação entre objeto e usuário (SCHNEIDER, 2010).

Dentre vários grupos de ruptura, um movimento importante no contexto do Novo Design foi o Grupo Memphis chamando os objetos de "antidesign". Para ele, o design deveria trabalhar numa perspectiva mais conceitual, colocando à prova a utilidade do objeto dentro da questão da não funcionalidade. Nessa época, Sottsass desenvolvia pesquisas que subvertiam totalmente o relacionamento tradicional dos móveis em seus espaços internos da casa. Para ele, o valor emocional em relação ao objeto não era dado por sua funcionalidade, mas também por sua expressividade, e isso foi o princípio do percurso do Novo Design.

Os objetos inspirados no movimento Memphis exploravam características importantes tais como: cores berrantes, forramentos em plástico estampado, lâmpadas coloridas e uma mistura de materiais inusitados, tais como, bronze com mármore, vidro e alumínio. Nesse momento, o avanço tecnológico permitia a mistura desses materiais, proporcionando infinitas possibilidades e variações. Azevedo relata a ideia memphisiana:

[...] surgiu para livrar-se de uma retórica institucional, e chama seus próprios trabalhos de gíria suburbana. A escola Memphis abre uma discussão bastante prática sobre a funcionalidade do design encarado sob o ponto de vista do pós-moderno. Ela assume a função utópica da utilidade, tornando seus móveis um verdadeiro play-ground opcional na sala de estar. Na estante Carlton, por exemplo, os livros ficam todos inclinados, já que se acredita que é sua vontade original (AZEVEDO, 1988, p. 64).

Schneider (2010) aponta que o objeto-estante "Carlton" de Ettore Sottsass, foi a peça mais retratada na década de 1980. Para Schneider (2010, p. 167), o grupo Memphis possibilitou, "[...] no sentido estético e concepcional, a eclosão 
de um conceito novo e ampliado de design. O grupo conduziu o design de volta ao lugar que ele já havia ocupado nos primórdios do Art Nouveau: o design arte". O movimento Memphis abre, então, uma discussão prática da funcionalidade do design, a partir do ponto de vista do pós-moderno, assumindo a função utópica da utilidade. Dá-se início a uma nova realidade de fazer projetos, que, segundo Moraes, trata-se de uma experiência multicultural dos anos 1980. Para o autor o designer colocou lado a lado "os valores simbólicos presentes na periferia de Milão e os signos provenientes de lugares longínquos como a Califórnia e a Índia" (MORAES, 2006, p. 161).

Foi a associação entre o design e a personalização estética dos produtos, que surgiu o caminho para o Novo Design. O grupo mencionado anteriormente defendia o design com humor, ironia e identificação com a arte. Pode-se afirmar que essas linguagens só são possíveis com a diluição das fronteiras entre a arte e o design. Nessa perspectiva arte e design não se opõem, se fundem.

Com isso a aproximação do design com a arte proporcionou, principalmente na década de 1990, o aumento de galerias de design em nível mundial. Durante muito tempo da história os designers foram levados a acreditar que o design não é arte e, sim; técnica e funcionalidade, sendo que alguns designers já reconheciam a contribuição da arte para o design, ente eles: Ron Arad, Marc Newson e os brasileiros Irmãos Campana, entre outros.

Esse contexto pode ser observado pela progressiva demanda da sociedade, no que tange às escolhas dos produtos com alto teor valorativo, isto porque já não existe distinção entre a forma técnica e abstrata dos objetos. Essa ruptura conceitual do objeto é uma característica do século XX. O indivíduo moderno vive uma relação contraditória com os objetos, ao Ihes solicitar sucessivos valores. Trata-se de uma relação sutil e efêmera com produtos capazes de seduzir e inebriar (DE MASI, 1999; SUDJIC, 2010). 
[...] rejeição ao funcionalismo; influências de subculturas (punk, etc.) e do cotidiano; tratamento eclético de estilos históricos; ironia, humor e provocação; trabalho experimental; utilização de materiais não usuais; formação de grupos; desligamento da produção industrial em série; produção de peças únicas e pequenas séries; uso dos meios de comunicação como pódio; transposição dos limites entre o design e a arte (SCHNEIDER, 2010, p. 166).

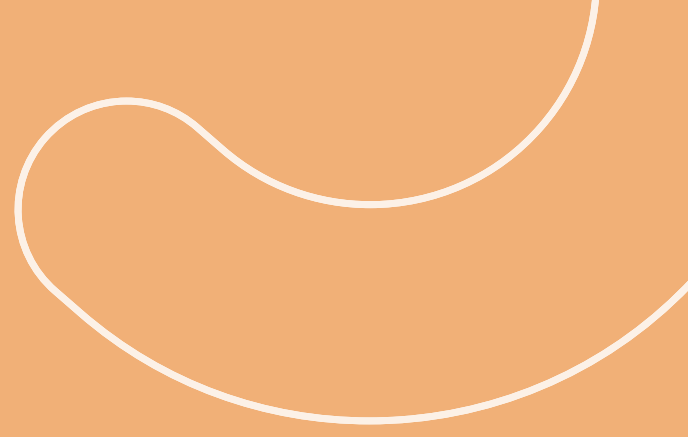


As artes plásticas no mundo tiveram sua história escrita num contexto social em que o design se enquadrava como seu subproduto. Essa relação não se dava evidentemente como inserção pura de produção de objetos usuais, mas como exercício de objetos sociais, chamados "artísticos" como, por exemplo, livros, tapeçarias e certos objetos de luxo. Porém, houve um desejo de uma nova inserção de arte na prática social, surgindo produtos distantes da arte como arte, e próximos do design. Esses novos produtos foram incorporados como frutos do Arte Design no uso cotidiano com finalidades muito específicas (TAVARES, 2007).

Para Tavares (2007), essa não separação, entre arte e design, talvez seja o alicerce da produção da arte e do design no contexto contemporâneo, confirmando o conceito de Novo Design dado por Schneider (2010). Isto porque as relações entre arte e design na atualidade já não se separam mais. O que se observa é uma confluência de linguagens que transitam entre esses dois mundos.

Poynor (2010) afirma que isso se deu em função de que, na metade dos anos de 1990, a complexidade desconstrutiva das criações dos designers deixou de ser uma questão crucial. Isto quer dizer que havia uma necessidade de evoluir da desconstrução para a oposição, ou seja, uma grande necessidade de mudar algo, confirmando a ascensão do Novo Design. A seguir, apresenta-se brevemente a crescente autonomia do Novo Design no Brasil.

\subsection{O NOVO DESIGN NO BRASIL: UMA PERSPECTIVA}

No que diz respeito ao Novo Design brasileiro Branzi(2006) relembra a importante contribuição que os designers, chamado por ele de "pais fundadores de uma tendência realmente independente do design brasileiro" (BRANZI, 2006, p. 17) nomeia e destaca alguns desses designers: 
Projética, Londrina, v. 11, n. 2, p. 179-205, agosto 2020

Lina Bo Bardi, Joaquim Tenreiro, José Zanine Caldas, Geraldo de Barros, Sérgio Rodrigues, Michel Arnoult e Norman Westwater [...] Bornancini e Pertzold, Osvaldo Mellone, Adriana Adam, Marcelo Resende, Carlos Motta, Luciano devia, Fulvio Nani Jr., Maurício Azeredo, Joaquim Redig e muitos outros ainda (BRANZI, 2006, p. 16).

Os nomes acima elencados indicam o período efervescente do design no Brasil, no período moderno e a partir de 1980, que movimentaram o cenário nacional. Nesse panorama pode-se perceber que a influência dessas discussões mundiais sobre design, atingiu principalmente o design de mobiliário. É importante relembrar que o design moderno brasileiro atingiu um grande reconhecimento no mundo, com alguns desses nomes elencados anteriormente.

Já nos anos de 1990, com a nova geração no Brasil, um número expressivo de designers vai se deixar influenciar pelo novo contexto do Novo Design. Assim Branzi (2006, p. 15) vai afirmar:

[...] se viu concluir finalmente o ciclo do pensamento da construção no Brasil, através de um fenômeno cultural unitário, constituído de um sistema produtivo nacional, de uma estratégia política generalista, e do papel compreensivo dos designers brasileiros, que operavam para realizar uma identidade latino-americana. De qualquer modo, começou a emergir a nova geração de mestres daquilo que chamaremos de Novo Design Brasileiro, constituído por Fernando e Humberto Campana, Edith Diesendruck, Fabio Falanghe e Giorgio Giorgi Jr. Jacqueline Terpins, Guto Índio da Costa, Flávia Alves de Souza, Fabíola Bergamo, Pedro Useche, Fernando Jaeger, Ângela Carvalho, GuinterParschalk, Dijon de Moraes e muitos outros.

A seguir destaca-se o trabalho de alguns desses representantes dessa geração pertencente ao Novo Design brasileiro, que são: Fernando e Humberto Campana, Edith Diesendruck e Jacqueline Terpins. 
Na década de 1980, o cenário nacional tem conhecimentodos designers Fernando e Humberto Campana, coincidindo com esse novo conceito registrado na linguagem das artes e do design mundial, o chamado Novo Design. Os objetos de Humberto e Fernando Campana foram expostos pela primeira vez em 29 de junho de 1989, na Galeria Nucleon8, na cidade de São Paulo. Foram cerca de 20 peças em ferro, sob o título de "As Desconfortáveis" (DARRIN, 2010, p. 69), apresentadas na figura a seguir.

Figura 1 - Coleção "As Desconfortáveis": Cadeira Positivo e Cadeira Negativo, 1989.

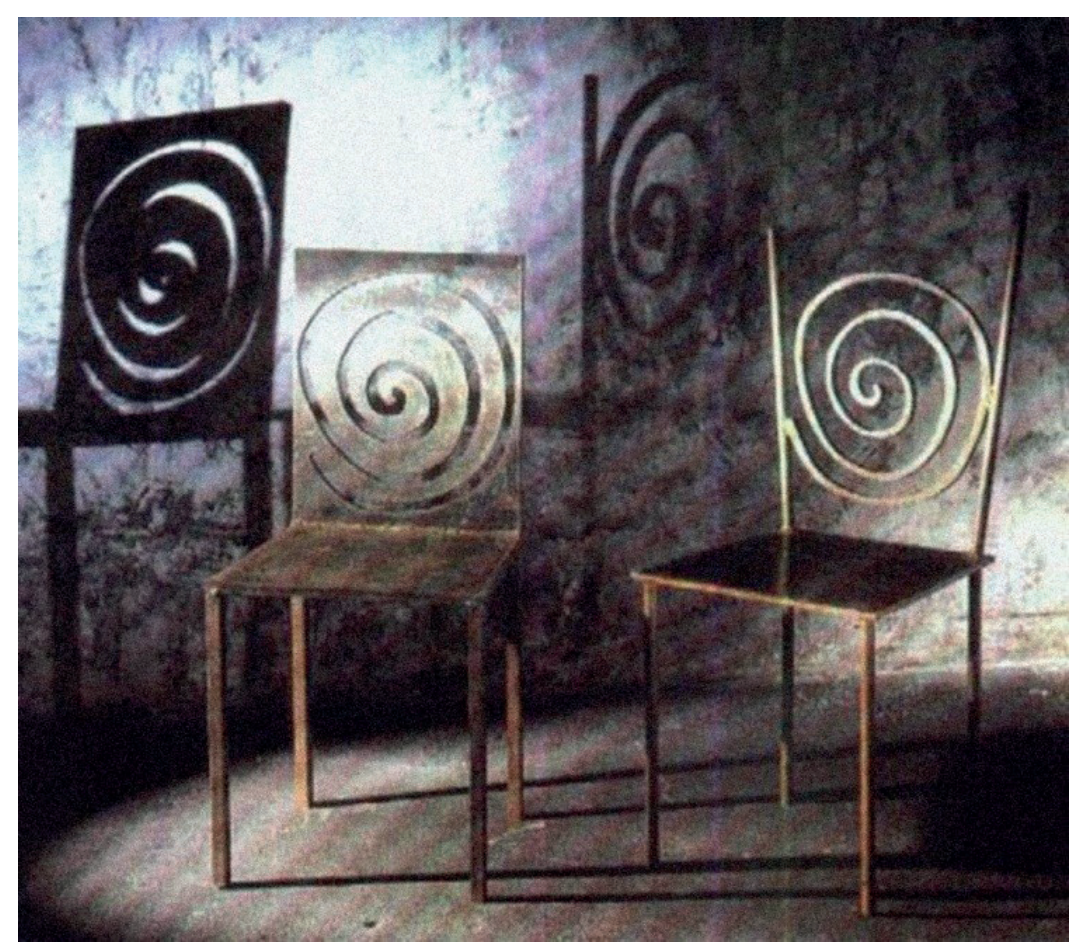

Fonte: Darrin (2010, p. 68).

Muito próximo da arte, o design produzido na coleção "As Desconfortáveis" permeia o conceito de Novo Design e pode ser denominado como Design-Arte (CHIARELLI, 2000; SCHNEIDER, 2010). 
Projética, Londrina, v. 11, n. 2, p. 179-205, agosto 2020

Neves (2009) menciona a exposição "As Desconfortáveis" de 1989 como um marco para o Novo Design brasileiro. A autora relata que a obra dos Irmãos Campana "[...] é um processo, uma atitude que vem sendo decodificada, deslocada, fruída e consumida no Brasil de forma significativamente positiva" (NEVES, 2009, p. 2.403).

Para Campana (2009), foi a partir dessa exposição que os dois designers descobriram a própria capacidade de criação

[...] descobrimos um vocabulário novo, encontramos nosso caminho. Os designers entenderam então que não compartilhavam da linguagem limpa e perfeita do design internacional como o italiano. Nossa ideia era tirar partido do erro - o erro de acabamento, de execução, tão comuns em nosso país, por causa da pressa da produção (CAMPANA, 2009, p. 34).

O relato anterior apresenta uma forma muito própria de criar, consolidando o conceito de design de autor. A coleção "As Desconfortáveis" apresentou uma nova experiência criativa, cuja referência deixou de ter a funcionalidade como requisito único. Essa presença do designer, tanto pela sua assinatura quanto , pelas qualidades semióticas, subjetivas e culturais, foi visto por Cauquelin (2005) como se o próprio designer se tornasse uma obra, um "astro" importante nessa rede que envolve seu trabalho, trata-se de uma estratégia que envolve a arte e o design, somando afetividade e emoção ao objeto.

Em 1995, os Irmãos Campana foram convidados a participar de um debate sobre o design brasileiro promovido pela Associazione per II Desegno Industriale (ADI), ocorrido no Palazzo Reale, em Milão. Esse evento serviu para certificar que a forma de fazer design que eles escolheram estava na contramão do conceito minimalista de design da época, confirmando o interesse do mercado internacional por seus objetos (CAMPANA, 2009). 
Em 1998, uma exposição realizada no MOMA (Museu de Arte Moderna de Nova York) com a curadora italiana Paola Antonelli ampliou a repercussão e o fascínio pela obra dos dois irmãos, onde Santos assevera: eles "modificaram o universo dos materiais no design de móvel" (SANTOS, 2015, p. 213). Esse cenário marcou a valorização de novas formas de projetar produtos, por meio de experimentações com materiais e novas tecnologias. Chiarelli comenta:

“Na década de 1980, quando os Campana estavam envolvidos com o cenário artístico brasileiro, o 'espírito da época' alimentava a possibilidade de todos os artistas usarem referências importantes de sua própria biografia e não apenas os 'grandes exemplos da arte"' (CHIARELLI, 2000, p. 41).

Ainda sobre os trabalhos apresentados, observa-se que o design produzido pelos Irmãos Campana sofre múltiplas influências, especialmente as culturais brasileiras. Pode-se afirmar que essa dupla de designers, é conduzida por uma inquietude criativa própria dos profissionais das artese do design (SCHNEIDER, 2010). Campana (2009, p. 37) os considera "[...] designers empreendedores, fazendo coisas no limite da arte" e ressalta que eles continuarão buscando "[...] a descontração, a criação, a emoção, a transformação e a reinvenção, multiplicando as possibilidades das nossas escolhas e das escolhas de quem vai usar um objeto concebido por nós".

Atualmente a dupla continua nessa perspectiva de criação, e assim conseguiu alcançar um reconhecimento internacional ímpar. Eles estão presentes nas galerias e museus de todo o mundo. O Vitra Design Museum na Alemanha, realizou em 2009 uma retrospectiva sobre a obra dos Campana, comemorando 20 anos de atuação no mercado, intitulada "Anticorpos Fernando \& Humberto Campana 1989-2009". Essa exposição percorreu a Europa e o Brasil, passando por Vila Velha (ES), Brasília, São Paulo e Rio de Janeiro e, posteriormente, Argentina, Chile, EUA e Ásia. 
Figura 2 - Capa do Catálogo Anticorpos e Luminária Broken Dreams

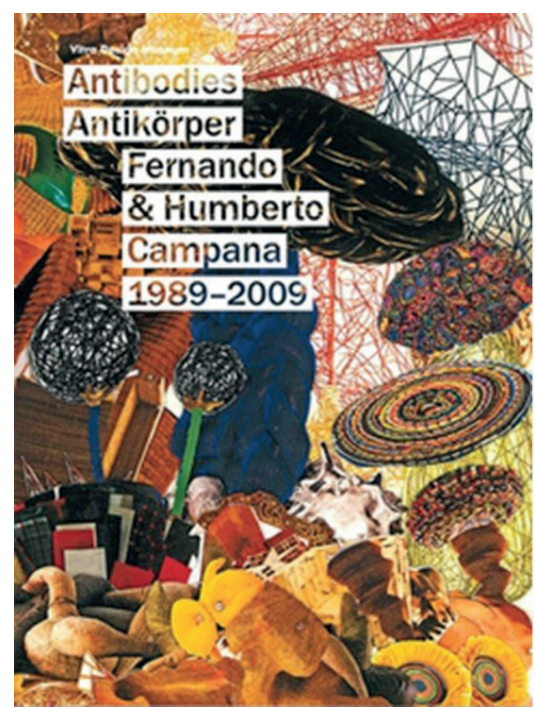

Catálogo da exposição Anticorpos - 2011

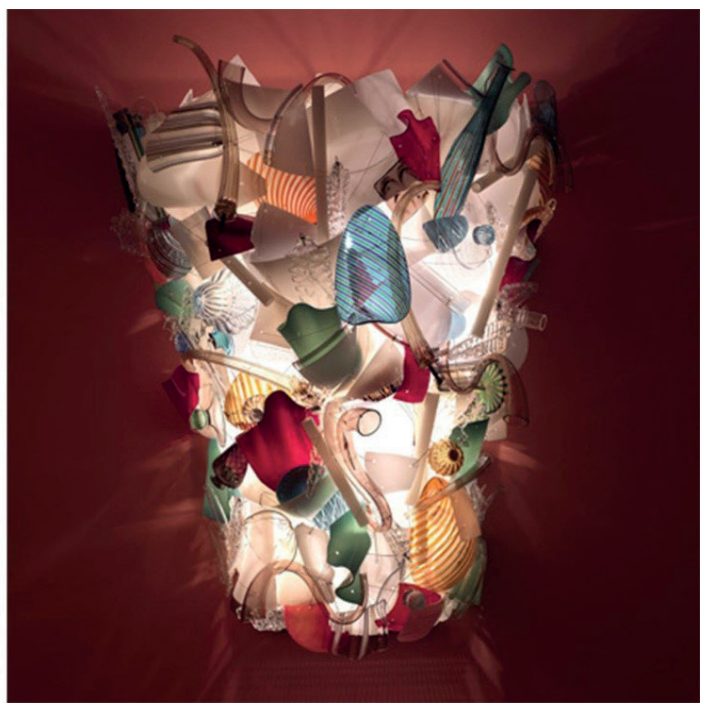

Luminária de parede presente na exposição Anticorpos, 2010, empresa Venini.

Fonte: Campana e Campana (2010, p. 292).

Para comemorar os quinze anos de existência do Museu Oscar Niemeyer MON em Curitiba, realizou-se de 27 de abril a 20 de agosto de 2017, a retrospectiva de trinta anos de carreira dos Irmãos Campana. A curadora da exposição Consuelo Cornelsen ressalta sobre o trabalho dos dois designers: eles "sempre tiveram como vocação o manejo de materiais simples e tantas vezes improváveis, ressignificando o conceito de função e construindo 'o grande a partir da valorização do singelo'" (MUSEU OSCAR NIEMEYER, 2017, p. 12). Juliana V. A. Vosnika complementa:

A atuação dos Campana apontou um novo campo que se abria para as propostas mais autorais do design de móveis e produtos, ampliando suas proposições e investigações expressivas num território de intercessão com a arte contemporânea, com dinâmicas equivalentes às deste mercado (MUSEU OSCAR NIEMEYER, 2017, p. 9). 
[...] se viu concluir finalmente o ciclo do pensamento da construção no Brasil, através de um fenômeno cultural unitário, constituído de um sistema produtivo nacional, de uma estratégia política generalista, e do papel compreensivo dos designers brasileiros, que operavam para realizar uma identidade latino-americana. De qualquer modo, começou a emergir a nova geração de mestres daquilo que chamaremos de Novo Design Brasileiro, constituído por Fernando e Humberto Campana, Edith Diesendruck, Fabio Falanghe e Giorgio Giorgi Jr. Jacqueline Terpins, Guto Índio da Costa, Flávia Alves de Souza, Fabíola Bergamo, Pedro Useche, Fernando Jaeger, Angela Carvalho, Guinter Parschalk, Dijon de Moraes e muitos outros (BRANZI, 2006, p. 15). 
Ainda hoje seus móveis e objetos são produzidos por empresas internacionais, tais como: Edra, Alessi, Fontana Arte e outras. Eles também possuem uma linha própria de objetos e móveis feita em seu estúdio em São Paulo, que são vendidas em galerias nacionais e internacionais, tais como: Albion Gallery em Londres, Fridman Benda em Nova York, Galeria O. em Roma, e Galeria Firma Casa em São Paulo. O forte da dupla é o trabalho com edições limitadas, assinadas e numeradas.

Outra representante desse Novo Design brasileiro é Edith Apter Diesendruck, formada em artes plásticas pela FAAP-Fundação Armando Álvares Penteado. A designer apresentou em 1991 na 6a edição do Prêmio MCB-Museu da Casa Brasileira, o lustrel, que ganhou o primeiro lugar na categoria equipamentos domésticos. A luminária é composta por fôrmas de empada, bocas de fogão, bolas de gude e fio de latão. A seguir apresenta-se as peças confeccionadas e premiadas pelo Museu da Casa Brasileira da designer Edith Diesendruck.

Figura 3 - Peças da designer Edith Diesendruck

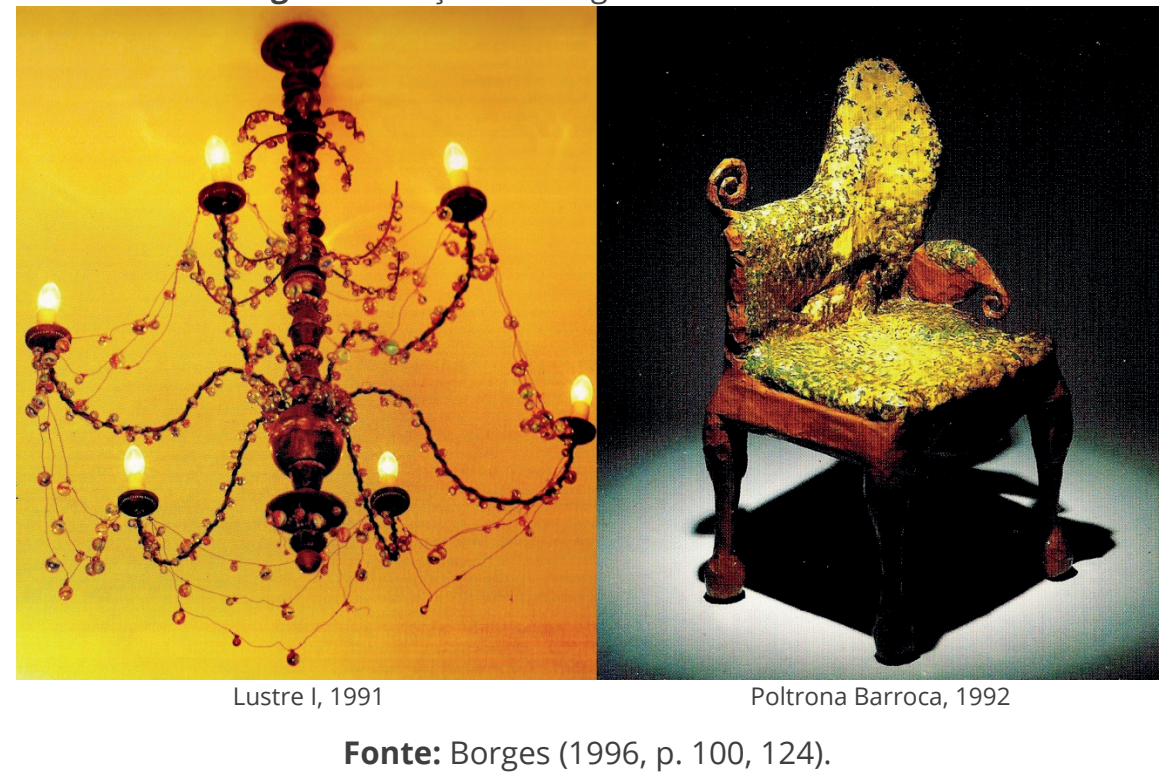


A $6^{a}$ edição do Prêmio Museu da Casa Brasileira, de 1991, marcou uma ruptura em relação aos anteriores, sendo que o resultado foi muito polêmico. Os jurados fixaram como critérios para premiação: originalidade, adequação aos aspectos culturais e ecológicos e binômio forma-função. Eles decidiram “conscientemente promover uma distribuição de prêmios de maneira equânime entre os produtos considerados design industrial e os de caráter mais conceitual." (BORGES, 1996, p. 98). Essa equanimidade na distribuição ao prêmio segundo Borges, "acabou por levar a um resultado esquizofrênico" (BORGES, 1996, p. 98). Ou seja, no momento em que essa discussão apenas se vislumbrava, obviamente as proposições desse movimento causaram percepções e reações diversas no cenário nacional.

Na $7^{\text {a }}$ edição do mesmo prêmio, no ano de 1993, a poltrona Barroca ganhou menção honrosa. A base é uma estrutura de tarugo de ferro soldado e uma tela de arame costurada no assento e encosto, e uma última camada de papel machê. Tudo isso revestido com decalques de damas antigas (BORGES, 1996).É importante destacar que a designer se envolve diretamente na elaboração de suas peças e, como ressalta Borges, ela "sabe soldar, esmerilhar, jatear, furar, lixar, etc" (BORGES, 1996, p. 100).

Um dos jurados, Décio Pignatari (1927-2012), destacou que o objeto é "uma verdadeira bricolagem, antítese dos conceitos mais estabelecidos do design no Brasil" (BORGES, 1996, p. 100). Acaso ou não, coincide com o momento de estabelecimento do "Novo Design" no Brasil.

Portanto, é fácil perceber que a aceitação dessa linguagem não é unanimidade. Ricardo Anderaós, jornalista da Folha de São Paulo reflete: O lustre confeccionado por Edith é "uma peça em metal com desenho tradicional, só que 'enfeitada' com fios de cobre e bolinhas de gude, na qual o acento lúdico se transforma em farsa" (BORGES, 1996, p. 100). A peça situa-se na fronteira entre 
Projética, Londrina, v. 11, n. 2, p. 179-205, agosto 2020

Arte e Design, e se apresenta em uma linha tênue e vaga abrindo espaço para um discurso crítico, atraindo a atenção para esse objeto de design singular.

É curioso ponderar que a designer confeccionou três peças do lustre, uma está no Museu da Casa Brasileira, o outro em sua casa, e o terceiro foi feito sob encomenda pelos designers Fernando e Humberto Campana. A designer destaca: estou interessada "em pesquisar novos materiais e linguagens, admite que não se preocupa com funcionalidade, muito menos em fazer peças vendáveis. Para ela, o design é uma forma de autoexpressão" (BORGES, 1996, p. 100).

Atualmente, Diesendruck elabora peças customizadas, com referências clássicas epeças exclusivas e assinadas, atuando em parceria com diversos designers. Diante disso, percebe-se que a designerse encontra num vanguardismo e estabelece uma estética própria e original. Nesse sentido Domenico De Masi (2014) chama esse tempo e ocasião de "momento mágico" e assevera:

Hoje o Brasil se encontra em uma situação única em relação ao seu passado e ao seu futuro. Depois de ter copiado por 450 anos a Europa e então outros cinquenta os Estados Unidos, agora que ambos os modelos-mito entram em uma crise profunda, o gigante latinoamericano está sozinho consigo mesmo, diante do seu futuro. Tratase de uma questão inquietante, que pode dissolver-se naconfusão ou pode gerar o modelo inédito de que o mundo precisa (DE MASI, 2014, p. 707).

A próxima designer representante também, do Novo Design brasileiro é Jacqueline Terpins, ela domina a técnica do sopro em vidro, e estudou na Penland School o fArt and Craft, nos Estados Unidos e depois estudou desenho na Byam Shaw School of Painting and Drawing na Inglaterra. Ela tem uma carreira sólida desde que se formou em 1970 e é considerada uma das designers contemporâneas mais relevantes. Além do vidro, Terpins trabalha com outros materiais, como a madeira, a cerâmica, o aço, além de experimentar e testar novos materiais. 
A seguir, é apresentada a poltrona Quatro, de 1999, e a mesa lateral BesameMucho, de 1991, numa versão em Corian.

Figura 4 - Mobiliário da designer Jaqueline Terpins

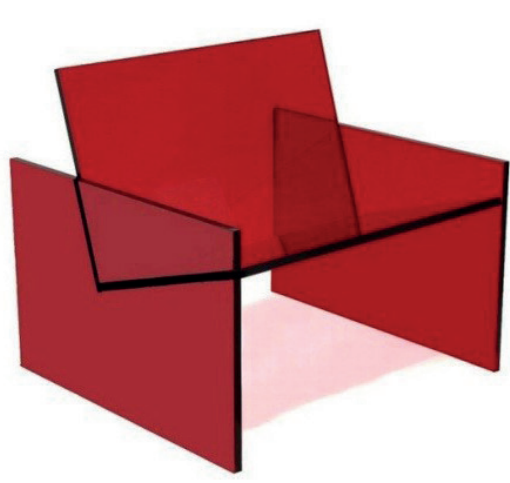

Poltrona Quatro, 1999

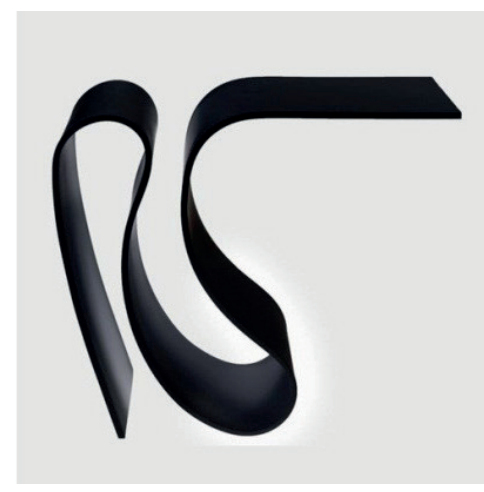

MesaBesameMucho, 1991

Fonte: Terpins (2016).

O estúdio de Jacqueline Terpins (2016) está localizado no térreo de um prédio antigo no bairro Pacaembu, um espaço com 180 metros quadrados, inaugurado em 2001. Ali ela produz, comercializa e distribui suas peças para o Brasil e o mundo, além de desenvolver peças em edições limitadas.

O trabalho da designer mescla tecnologia ao acabamento artesanal primoroso, características que balizam os seus produtos. Um dos mais recentes trabalhos, em edição limitada, é o aparador Cello, de 2014. Foram executadas trinta peças em madeira talhada e aço inox. O aparador tem um movimento contínuo e fluído desde a parte superior até as suas extremidades com três pontos de apoio. 
Hoje o Brasil se encontra em uma situação única em relação ao seu passado e ao seu futuro. Depois de ter copiado por 450 anos a Europa e então outros cinquenta os Estados Unidos, agora que ambos os modelos-mito entram em uma crise profunda, - gigante latino-americano está sozinho consigo mesmo, diante do seu futuro. Trata-se de uma questão inquietante, que pode dissolver-se na confusão ou pode gerar o modelo inédito de que o mundo precisa (DE MASI, 2014, p. 707).

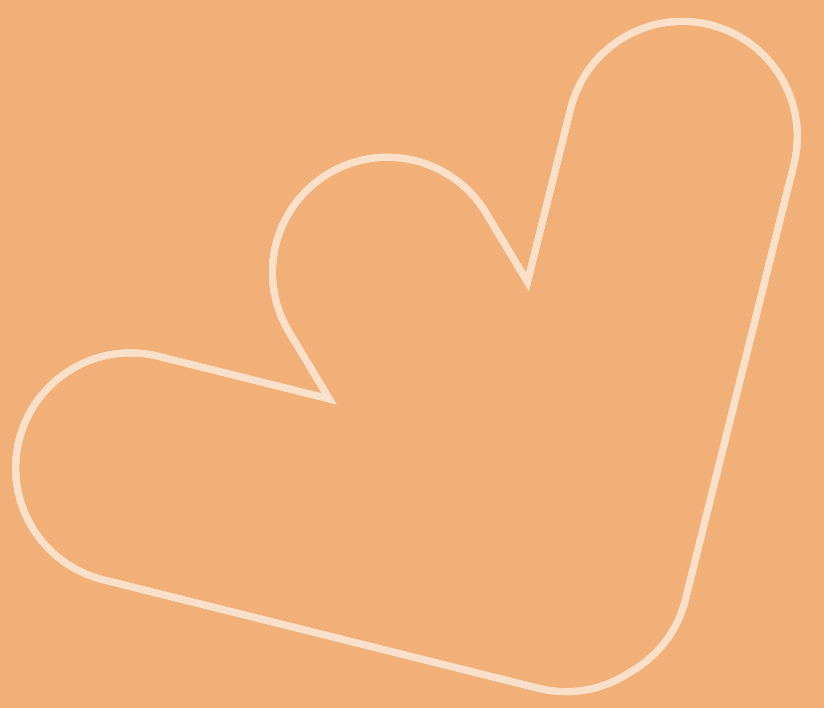


Figura 5 - Aparador Cello, 2014

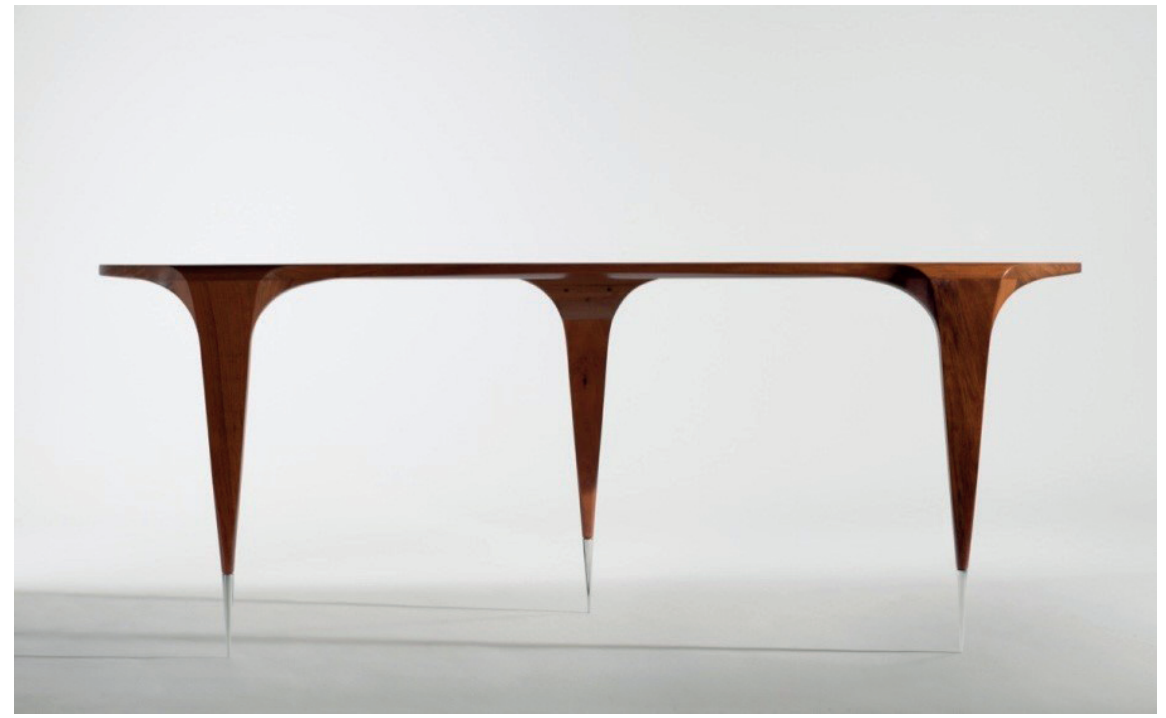

Fonte: Terpins (2016).

A peça possui uma elegância e alcançou uma sofisticação em sua linguagem e um purismo de forma excepcional. Nesse contexto, fica a convicção de um real amadurecimento dessa geração de criadores e o fortalecimento do elo entre linguagem, expressão e execução, por meio de um repertório que se amplia para além de influências estilísticas e se aprofunda em métodos próprios. Nesse sentido é possível concordar com Lipovetsky e Serroy $(2015$, p. 163) quando afirmam: "O Brasil se tornou um verdadeiro ator na cena do design". E essa questão não deveportanto ser ignorada pelos estudiosos do tema.

\section{CONSIDERAÇÕES FINAIS}

Pode-se entender que, a partir do Novo Design surge uma corrente de objetos-conceito feita por designers que se apropriam da forma plástica da arte para personificar suas soluções de projeto. Tanto na arte como no design, surgem objetos 
Projética, Londrina, v. 11, n. 2, p. 179-205, agosto 2020

em que a fronteira existente entre a utilidade e a estética é cada vez mais tênue. Tavares (2007) entende que a falta de distinção desses objetos é o principal motivo das variações conceituais dadas ao design atualmente. E esse autor, acredita surgir daí um design mais processual, em que a imaterialidade dá ao objeto diferentes plasticidades.

Pode-se dizer que o conceito de Novo Design é considerado a chave do período pós-moderno e a junção entre a arte e o design, proporcionou uma linguagem singular, confirmando essa designação para as produções do Novo Design. Entende-se, portanto que, historicamente, o processo de aproximação com o Novo Design foi transformador para essa geração, onde os designers utilizaram diversos materiais e novas técnicas, criando assim novos símbolos e dando novos sentidos a estes símbolos. Pode-se afirmar que essa estética foi uma possibilidade dentre tantas outras já exploradas.

É possível perceber no conceito do Novo Design momentos de desconstrução e apropriação de elementos característicos da arte, validando o conceito de Design Arte. Muito mais que um simples conceito, o Novo Design representa uma etapa própria do design contemporâneo, em que as influências anteriores da década de 1980 foram somadas ao desejo de se ter a arte e outras disciplinas impressas nas peças desenvolvidas a partir dessa linguagem.

A aproximação do design com a arte proporcionou soluções que vem sendo cada vez mais reconhecidas, e se intensificou principalmente nas duas primeiras décadas do século XXI. Dessa interação, o que era antes para a arte um mero exercício criativo da cultura de um artista fez surgir essa nova categoria de objetos: fortes culturalmente e ricos em soluções de projeto.

O Novo Design se constituiu em um novo estatuto narrativo, que se potencializa com esse novo lugar de edição, exposição e comercialização desses 


\section{O Novo Design no Brasil: a construção de um conceito \\ DORNAS, A.; LANA, S. L. B.; ALMEIDA, M. G.}

objetos, podemos então considerar, que o tempo e espaço presentes no Novo Design pertencem a um momento distinto de produção, onde esse novo contexto, se associa mais a linguagem e menos a funcionalidade.

A partir dos designers apresentados anteriormente, surge uma geração de criadores que consolidam uma linguagem, ainda difícil de ser conceituada, que se baseia em um amplo hibridismo. Esse hibridismo não se limita somente a diluição das fronteiras entre arte e design. Fica explícito com a apresentação desses designers brasileiros, que em maior ou menor grau, esses profissionais escolhem caminhos próprios para projetar e muitas vezes partem para novas demandas de trabalho e criam novas categorias de projeto. 
Projética, Londrina, v.11, n.2, p. 179-205, agosto 2020

\section{REFERÊNCIAS}

1. AZEVEDO, Wilton. O que é design? São Paulo: Brasiliense, 1988.

2. BARROSO NETO, Eduardo. Design, identidade cultural e artesanato. In: JORNADA IBERO-AMERICANA DE DESIGN NO ARTESANATO, 1., 1999, Fortaleza. Anais [...]. Fortaleza: JIADA, 1999. v. 1. Disponível em: http://www.eduardobarroso.com.br/artigos.htm. Acesso em: 4 mar. 2011.

3. BORGES, Adélia. Museu da casa brasileira. Prêmio Design: 1986-1996. São Paulo: Museu da Casa Brasileira, 1996.

4. BRANZI, Andrea. Prefácio: o Brasil como modelo do mundo. In: MORAES, Dijon. Análise do design brasileiro: entre mimese e mestiçagem. São Paulo: Edgard Blücher, 2006. p. 3-17.

5. BÜRDEK, Bernhard E. História, teoria e prática do design de produtos. São Paulo: Edgard Blucher, 2006.

6. CAMPANA, Fernando; CAMPANA, Humberto. Campana brothers: complete works (so far). New York: Rizzoli, 2010.

7. CAMPANA, Humberto. Cartas a um jovem designer: do manual a indústria, a transformação dos Campana. Rio de Janeiro: Elsevier, 2009.

8. CAUQUELIN, Anne. Arte contemporânea: uma introdução. São Paulo: Martins, 2005.

9. CHIARELLI, Tadeu. Do objeto impossível à possibilidade do objeto. In: MUSEU DE ARTE MODERNA DE SÃO PAULO. Entre o design e a arte: irmãos Campana. São Paulo: MAM, 2000. p. 39-49.

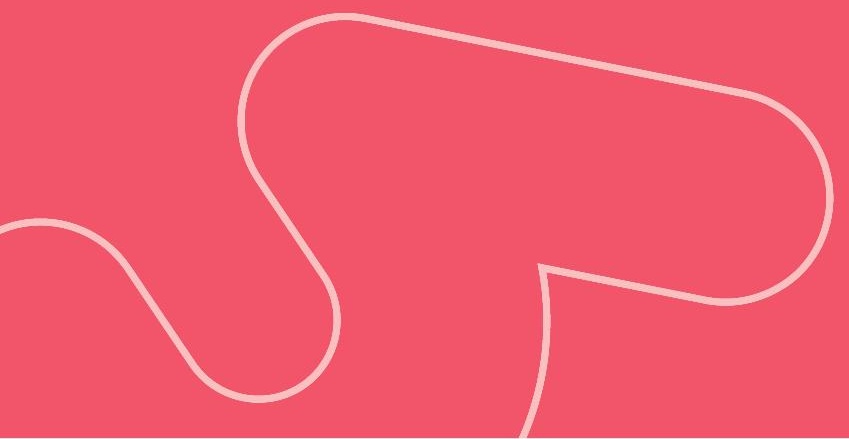


O Novo Design no Brasil: a construção de um conceito

DORNAS, A.; LANA, S. L. B.; ALMEIDA, M. G.

10. DARRIN, Alfred. Section 2 and 3. In: CAMPANA, Fernando; CAMPANA, Humberto. Campana brothers: complete works (so far). New York: Rizzoli, 2010. p. 66-298.

11. DE MASI, Domenico (org.). A sociedade pós-industrial. 2. ed. São Paulo: Ed. do SENAC, 1999.

12. DE MASI, Domenico. O futuro chegou: modelos de vida para uma sociedade desorientada. Rio de Janeiro: Casa da Palavra, 2014.

13. DIAS, Maria Regina Álvares Correia. Percepção dos materiais pelos usuários: modelo de avaliação Permatus. 2009. 280 f. Tese (Doutorado em Engenharia e Gestão do Conhecimento) - Universidade Federal de Santa Catarina, Florianópolis, 2009.

14. HEINICH, Nathalie. Práticas da arte contemporânea: uma abordagem pragmática a um novo paradigma artístico. Sociologia \& Antropologia, Rio de Janeiro, v. 4, n. 2, p. 373-390, 2014. Disponível em: http://dx.doi.org/10.1590/ 2238-38752014v424. Acesso em: 15 nov. 2014.

15. LIPOVETSKY, Gilles; SERROY, Jean. A estetização do mundo: viver na era do capitalismo artista. São Paulo: Companhia das Letras, 2015.

16. MANZINI, Ezio; MERONI, Anna. Design e transformação. In: KRUCKEN, Lia. Design e território: valorização de identidades e produtos locais. São Paulo: Studio Nobel, 2009. p. 13-16. 
Projética, Londrina, v.11, n.2, p. 179-205, agosto 2020

17. MORAES, Dijon de. Análise do design brasileiro: entre mimese e mestiçagem. São Paulo: Edgard Blücher, 2006.

18. MUSEU OSCAR NIEMEYER. Irmãos Campana. Curitiba, PR: Museu Oscar Niemeyer, 2017. 216p. Textos: Juliana Vellozo Almeida Vosnika [et al.]. Tradução: Cecília Bergamo e Luigi Barichello. Curadoria: Consuelo Cornelsen. Catálogo da Exposição MON de 27 abr. a 20 ago. 2017. ISBN 978-85-60638-50-5 1.

19. NEVES, Maryclea. Campana e Duchamp: design ready to make arte no MAM. In: ENCONTRO DA ASSOCIAÇÃO NACIONAL DE PESQUISADORES EM ARTES PLÁSTICAS TRANSVERSALIDADES NAS ARTES VISUAIS, 2009, Salvador, BA. Anais [...]. Salvador: ANPAP, 2009. Disponível em: http://www.anpap.org.br/ anais/2009/pdf/chtca/maryclea_carmona_m aues_neves.pdf. Acesso em: 15 jun. 2011.

20. POYNOR, Rick. Abaixo as regras. Porto Alegre: Bookman, 2010.

21. SANTOS, Maria CecíliaLoschiavo dos. Móvel moderno no Brasil. 2. ed. São Paulo: Editora Olhares, 2015.

22. SCHNEIDER, Beat. Design: uma introdução: o design no contexto social, cultural e econômico. São Paulo: Blucher, 2010.

23. SUDJIC, Deyan. Meaning beyond utility: the Campana brothers and postindustrial design. In: CAMPANA brothers: complete works (so far). New York: Rizzoli, 2010. p. 40-47.

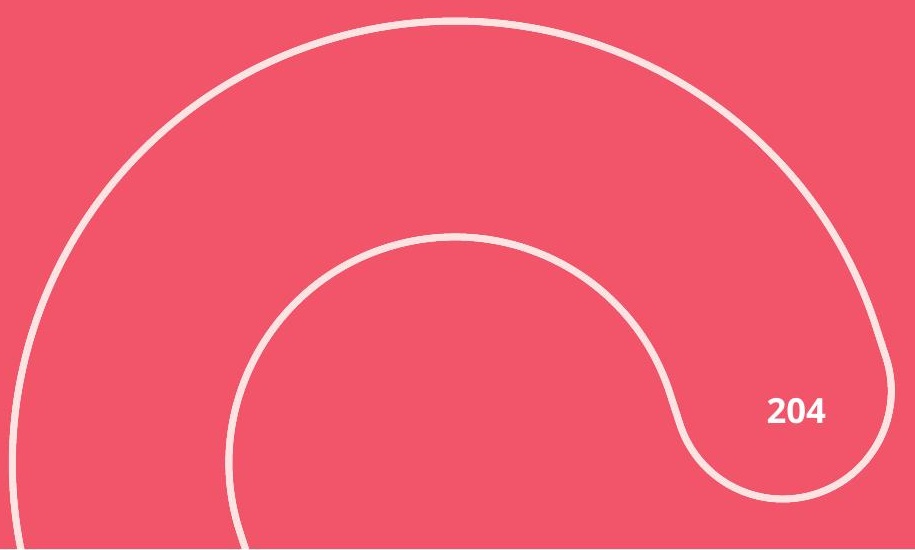


O Novo Design no Brasil: a construção de um conceito DORNAS, A.; LANA, S. L. B.; ALMEIDA, M. G.

24. TAVARES, Mônica. Arte-design: a produção do sentido. In: ENCONTRO DA ASSOCIAÇÃO NACIONAL DOS PROGRAMAS DE PÓS-GRADUAÇÃO EM COMUNICAÇÃO, 16., 2007, Curitiba, PR. Anais [...]. Curitiba: UTP, 2007. Disponível em: http://www.compos.org.br/data/biblioteca_234.pdf. Acesso em: 10 jun. 2011.

25. TERPINS. Estúdio Jaqueline Terpins. Disponível em: http://www.terpins.com/ Curriculum.html. Acesso em: 12 dez. 2016.



